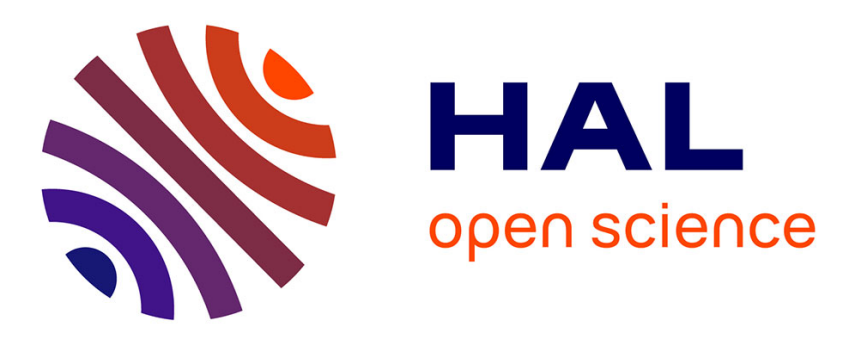

\title{
Graphene-based nanomaterials in innovative electrochemistry
}

Sabine Szunerits, Rabah Boukherroub

\section{To cite this version:}

Sabine Szunerits, Rabah Boukherroub. Graphene-based nanomaterials in innovative electrochemistry. Current Opinion in Electrochemistry, 2018, 10, pp.24-30. 10.1016/j.coelec.2018.03.016 . hal02189339

\section{HAL Id: hal-02189339 \\ https://hal.science/hal-02189339}

Submitted on 19 Jul 2019

HAL is a multi-disciplinary open access archive for the deposit and dissemination of scientific research documents, whether they are published or not. The documents may come from teaching and research institutions in France or abroad, or from public or private research centers.
L'archive ouverte pluridisciplinaire HAL, est destinée au dépôt et à la diffusion de documents scientifiques de niveau recherche, publiés ou non, émanant des établissements d'enseignement et de recherche français ou étrangers, des laboratoires publics ou privés. 


\title{
Graphene-based nanomaterials in innovative electrochemistry
}

\author{
Sabine Szunerits ${ }^{1 *}$, Rabah Boukherroub ${ }^{1}$ \\ ${ }^{1}$ Univ. Lille, CNRS, Centrale Lille, ISEN, Univ. Valenciennes, UMR 8520-IEMN, F-59000 \\ Lille, France
}

\section{RESEARCH HIGHLIGHTS}

- Graphene and its derivatives play an important role in today's electrochemical based technologies as outlined in this article

- Examples are given for energy driven applications and electrocatalytic processes with the aim to replace $\mathrm{Pt} / \mathrm{C}$ bench mark electrode

- The high performance of graphene-based electrodes in biosensing and biomedical driven applications is presented

To whom correspondence should be send to: sabine.szunerits@univ-lille1.fr 


\section{Introduction}

Electrochemical science has become a discipline of wide scientific and technological interest due to the important role in present-day technologies. Batteries, fuel cells, supercapacitors, electrochromic devices, gas separation membranes, and sensors are some examples of applications of electrode materials. The success in electrochemical technology is largely due to the continued design and development of novel material electrodes that meet the needs of modern society. Emerging two-dimensional nanomaterials, including next to graphene, h-BN, $\mathrm{MoS}_{2}, \mathrm{NbSe}_{2}, \mathrm{TiS}_{2}, \mathrm{TaS}_{2}, \mathrm{WS}_{2}, \mathrm{WSe}_{2}, \mathrm{TaSe}_{2}$, etc., metal-organic frameworks (MOFs) and many more, are at the forefront of interest because of their superior potential for electrochemically driven applications in many different fields [1-4]. The success of graphenebased electrode materials, such as chemical vapor deposition produced graphene as well as chemically derived graphene derivatives, in numerous electrochemical based technologies (Figure 1) is due to a number of factors, which are key to most of the applications [4-7].

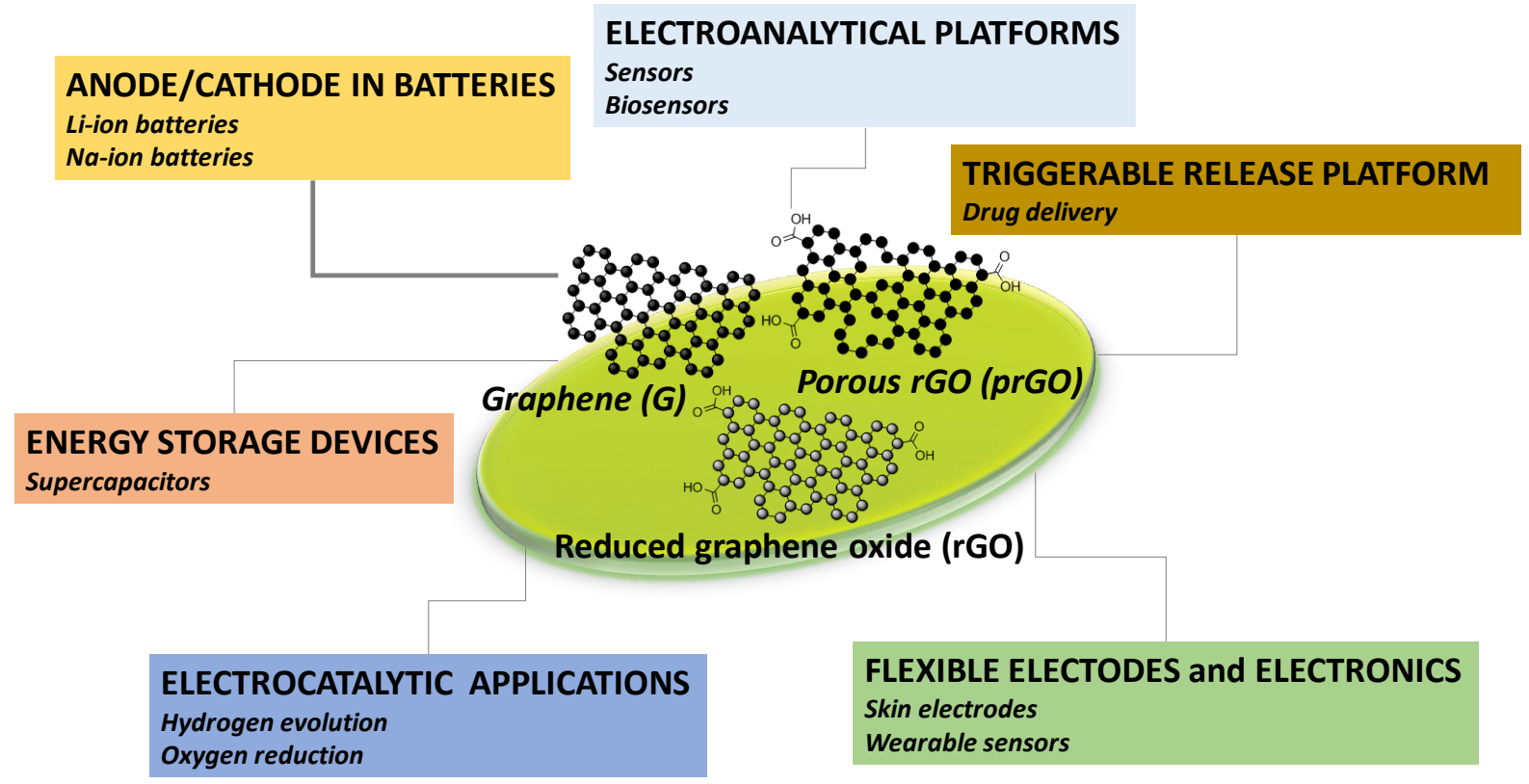

Figure 1: Graphene interfaces for innovative electrochemical based applications.

Indeed, graphene exhibits a large surface area, which can be further tuned through the generation of porous structured graphene and incorporation of dopants. Additionally, graphene as a highly conjugated network ( $\pi$-conjugation) bears hydrophobic properties providing an ideal platform for immobilizing organic and inorganic molecules in an easy manner. Graphene exhibits also high conductivity and mediates electron transfer mostly at its edge planes [8]. Those properties have made graphene of potential interest for electrochemical and biosensing oriented applications. To evaluate graphene's performance as an electrode 
material, the heterogeneous electron transfer (ET) rate between graphene and a redox mediator has to be determined and compared with its naturally occurring counterpart 3-D graphite.[9,10] The literature offers some contrasting views on the reactivity of mono and multilayered graphene. Accelerated kinetics data are reported on mechanically exfoliated monolayer graphene compared to bilayer graphene and graphite.[11,12] Guell et al. observed increased ET kinetics with increasing number of CVD stacked graphene flakes (from 1 to 7) using a ferrocene derivative as a mediator. However, no increased ET was observed at the edges or steps in comparison to the basal plane.[13] To shed more light into the electrochemistry of graphene, Velicky et al. determined the electron transfer rates of three redox mediators on mechanically exfoliated graphene layers (1-100) supported on insulating $\mathrm{Si} / \mathrm{SiO}_{2}$ substrates. A large variation in kinetics is observed across the basal plane of the same flake, indicating that local surface conditions affect the electron transfer kinetics. While the growing number of commercial sources of graphene represents certainly an important step towards the commercialization of graphene-based materials in the near future, for a large number of electrochemical applications, it is not graphene but chemically derived reduced graphene oxide (rGO) which is used. In contrast to pristine graphene, rGO contains lattice defects and residual oxygen-containing groups. While these defects impact on the electrical readout, they are actually beneficial to achieve fast heterogeneous electron transfer. Additionally, the presence of oxygen-containing groups offers plenty of opportunities for covalent immobilization of surface ligands to target specific sensing or drug delivery applications $[8,14]$. The promising electrochemical characteristics such as large potential window, fast electron transfer kinetics and increased capacitance of rGO based materials together with their low cost of production make them ideal materials for electrochemicaldriven applications $[14,15]$.

This article is not aiming to discuss in details all the different recent examples of rGO based electrochemical applications ranging from energy to electroanalytical and biosensing driven applications. It should be seen as a general review to a broad audience interested in graphene based electrochemistry and its different aspects. The review will thus highlight some important works with details to be found in the respective articles. It will also address certain aspects to further enhance the use of graphene nanomaterials in innovative electrochemical designs.

\section{Recent examples from the literature}

\section{Energy driven applications: Energy storage and energy conversion}


The development of novel materials for energy storage is of great importance to fulfill the increasing demand of energy. Lithium ion batteries are highly promising devices for powering portable electronics and also electrical vehicles. Currently, the use of graphite anodes with a theoretical capacity of $372 \mathrm{mAh} \mathrm{g}^{-1}$ has become insufficient to satisfy the increasing energy and power densities demand, making the search for efficient and stable anode materials possessing high lithium capacity of high importance. Mullins and co-workers developed a composite of N-doped rGO and nanocrystalline tin sulfides and tested it as anode in lithium batteries [16]. When cycling at a specific rate of $0.2 \mathrm{~A} \mathrm{~g}^{-1}$, a Coulombic capacity of $562 \mathrm{mAh}$ $\mathrm{g}^{-1}$ was retained after the $200^{\text {th }}$ cycle, which is believed to be due to the presence of conductive rGO cushioning the stress associated with the expansion of lithiation of Sn. Lin et al. reported a composite lithium metal anode composed of $7 \mathrm{wt}$ \% layered rGO with nanoscale gaps that can host metal lithium. The composite exhibited low dimensional variations $(20 \%)$ during cycling, good mechanical flexibility next to retaining up to $3.390 \mathrm{~mA} \mathrm{~g}^{-1}$ of capacity in a carbonate electrolyte [17]. Graphene encapsulated Si microparticles were proposed by Li as anode in lithium ion batteries, where the graphene cage acts as a flexible and mechanically strong buffer during deep galvanostatic cycling, allowing the microparticles to expand and fracture within the cage while retaining electrical connectivity on both the particle and electrode levels.

Among the new battery chemistries being developed, sodium-ion batteries are considered to be the most promising ones due to similar intercalation chemistry to Li-ion ones and natural abundance of sodium resources. Anodes of rGO, with uniformly anchored $\mathrm{Fe}_{2} \mathrm{O}_{3}$ single crystallites with a particle size of $\approx 300 \mathrm{~nm}$ displayed a reversible capacity of $610 \mathrm{mAh} \mathrm{g}^{-1}$ at $50 \mathrm{~mA} \mathrm{~g}^{-1}$, high coulombic efficiency ( $71 \%$ for the first cycle) and a good cyclability with $82 \%$ capacity retention after 100 cycles, suggesting a potential feasibility for sodium-ion battery [18]. The $\mathrm{Na}^{+}$intercalation/de-intercalation properties of mesoporous $\mathrm{WO}_{3-\mathrm{x}}$ encapsulated in $\mathrm{N}$-doped macroporous graphene, formed by heat treatment of a co-assembly of amine-functionalized mesoporous silica/metal oxide and GO with subsequent silica removal, were recently demonstrated by Kim et al. [19].

To tackle the challenge in the preparation of high-capacity electrode materials with good structural stability and flexibility, Mo et al. proposed a 3D interconnected porous nitrogendoped graphene foam (NGF) with encapsulated Ge quantum dots@ nitrogen-doped graphene (Ge-QD@NG), exhibiting high specific capacity of $1.220 \mathrm{mAh} \mathrm{g}^{-1}$ and long cycling capability [20]. It is well recognized that the ever-growing demands in future flexible electronics such as 
wearable devices, portable implants, biomedical products, have aroused a worldwide research interest in the development of electrodes that maintain their conductivities under repeated stretching deformation. A solid-state electrochemical capacitor was recently developed using wavy rGO displaying a specific capacitance of $67.25 \mathrm{mF} \mathrm{cm}^{-2}$ at a current density of $1 \mathrm{~mA}$ $\mathrm{cm}^{-2}$, and excellent stability [21].

Next to batteries, supercapacitors (SC) are the key devices for energy storage due to their high specific capacitance, high power density, ultrafast charging/discharging rate, extremely low internal discharge, long cycle life (300.000 cycles) and low cost [22,23]. We reported recently on an all solid-state $\mathrm{SC}$ using $\mathrm{N}$-doped porous $\mathrm{rGO}$ with a specific capacity of $230 \mathrm{~F} \mathrm{~g}^{-1}$ at $1 \mathrm{~A}$ $\mathrm{g}^{-1}$ current density and good capacitance retention up to $88 \%$ even after 10.000 galvanostic charge/discharge cycles recorded at $5 \mathrm{~A} \mathrm{~g}^{-1}$ (Figure 2A) [23]. While symmetric SC have many reported outstanding properties, asymmetric designs using graphene-based materials as negative electrode materials allowed widening the negative working potential range. A high performance asymmetric $\mathrm{SC}$ using $\mathrm{MnCo}_{2} \mathrm{O}_{4}$ nanofibers as anode and $\mathrm{N}$-doped $\mathrm{rGO}$ aerogels as cathode was proposed [24]. The $\mathrm{MnCo}_{2} \mathrm{O}_{4}$ nanofibers store negative charges such as solvated $\mathrm{OH}^{-}$, while the $\mathrm{N}$-doped $\mathrm{rGO}$ aerogel stores positive charges, providing an operating potential of $1.8 \mathrm{~V}$ with energy and power densities of $54 \mathrm{Wh} \mathrm{kg}^{-1}$ and $9851 \mathrm{~W} \mathrm{~kg}^{-1}$, respectively and $85.2 \%$ capacity retention over 3.000 cycles. The charge storage mechanism of the spinel-type oxide materials remains however unclear, even though synchrotron-based X-ray absorption spectroscopy (XAS) was used to determine the oxidation states of Co and $\mathrm{Mn}$ at the $\mathrm{MnCo}_{2} \mathrm{O}_{4}$ electrode after being electrochemically tested.

Last but not least, microbial fuel cells are perceived as a promising renewable power source harvesting electricity from organic matter by microorganisms. Their practical application is still greatly impeded by their lower power density compared to conventional fuel cells, mainly due to the sluggish extracellular electron transfer and low bacteria loading. 3D hierarchically structured porous MWCNTs/rGO nanohybrids were found to be useful anode materials for the growth of rich bacterial biofilms, displaying a power density of $789 \mathrm{~mW} \mathrm{~m}^{-2}$ in Shewanella putrefaciens CN32 microbial fuel cells (Figure 2B), being 6-fold higher than that of conventional carbon cloth [25].

\section{Catalytic driven reaction}


Metal nanoparticle-rGO composites have been largely investigated as advanced electrode materials due to their interesting electrocatalytic features. Introduction of rGO to the catalytic system enhances the catalytic activity not only due to its large surface area, high conductivity and excellent electrochemical properties, but also as rGO stabilizes efficiently the catalytic nanostructures from aggregation. Such nanocomposites have found widespread applications for green and renewable sources of energy, including electrochemical water splitting reaction, putting oxygen evolution reaction (OER) and hydrogen evolution reaction (HER) at the forefront of interest. Similarly, the oxygen reduction reaction (ORR) is important to renewable energy technologies, including fuel cells and metal-air batteries. Platinum based catalysts have long been used for ORR and HER, and carbon supported platinum (Pt/C) is still one of the bench mark catalysts [26]. Indeed, based on its adsorption energetics of the $\mathrm{H}$ atom, platinum is the optimal material for fuel cell electrocatalysis. The high cost of platinum and low catalytic efficiency due to $\mathrm{CO}$ poisoning along with thermal instability remain nevertheless the major limiting factors for enhancing the energy-conversion efficiency in fuel cells and other energy driven devices. Non-Pt group electrocatalysts and even metal-free catalysts have shown their efficiency towards the different electrocatalytic processes [3]. For example, CoMn oxide nanoparticles (Co:Mn ratio of 2:1) supported over $\mathrm{N}$-doped porous reduced graphene displayed ORR activity under basic conditions comparable to that of commercial Pt/C catalyst (Figure 2C), where the high activity was attributed to the cooperative effect arising from the metal entities and the defects in N-doped porous rGO [27]. $\mathrm{PdAg}$ particles embedded on $\mathrm{ZrO}_{2}$ /porous carbon/rGO nanocomposites resulted in electrodes with excellent activity for the dehydrogenation of formic acid with $100 \%$ hydrogen selectivity [28]. Zheng et al. demonstrated that g- $\mathrm{C}_{3} \mathrm{~N}_{4} @ \mathrm{~N}$-doped reduced graphene oxide was a highly efficient metal-free HER catalyst [29]. Tri-doped rGO (nitrogen, phosphorus, fluorine), obtained by thermal activation of a mixture of polyaniline-coated GO and ammonium hexafluorophosphate, was found to exhibit excellent electrocatalytic activities for ORR, OER and HER and could be used as an OER-HER bifunctional catalyst for oxygen and hydrogen gas production in an electrochemical water-splitting unit, which was powered by an integrated $\mathrm{Zn}$-air battery based on an air electrode made from the same electrocatalyst for ORR (Figure 2D) [30]. 


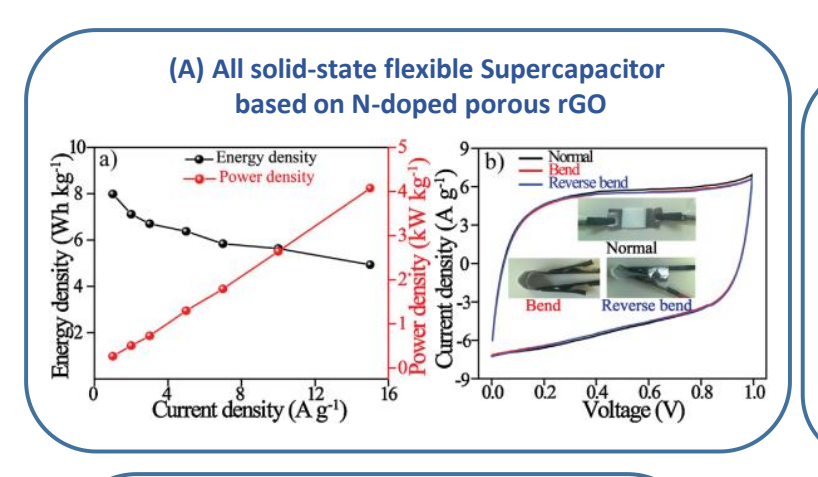

(C) Oxygen Reduction catalyzed by N-doped prGO/CoMn

(B) Microbial fuel cells
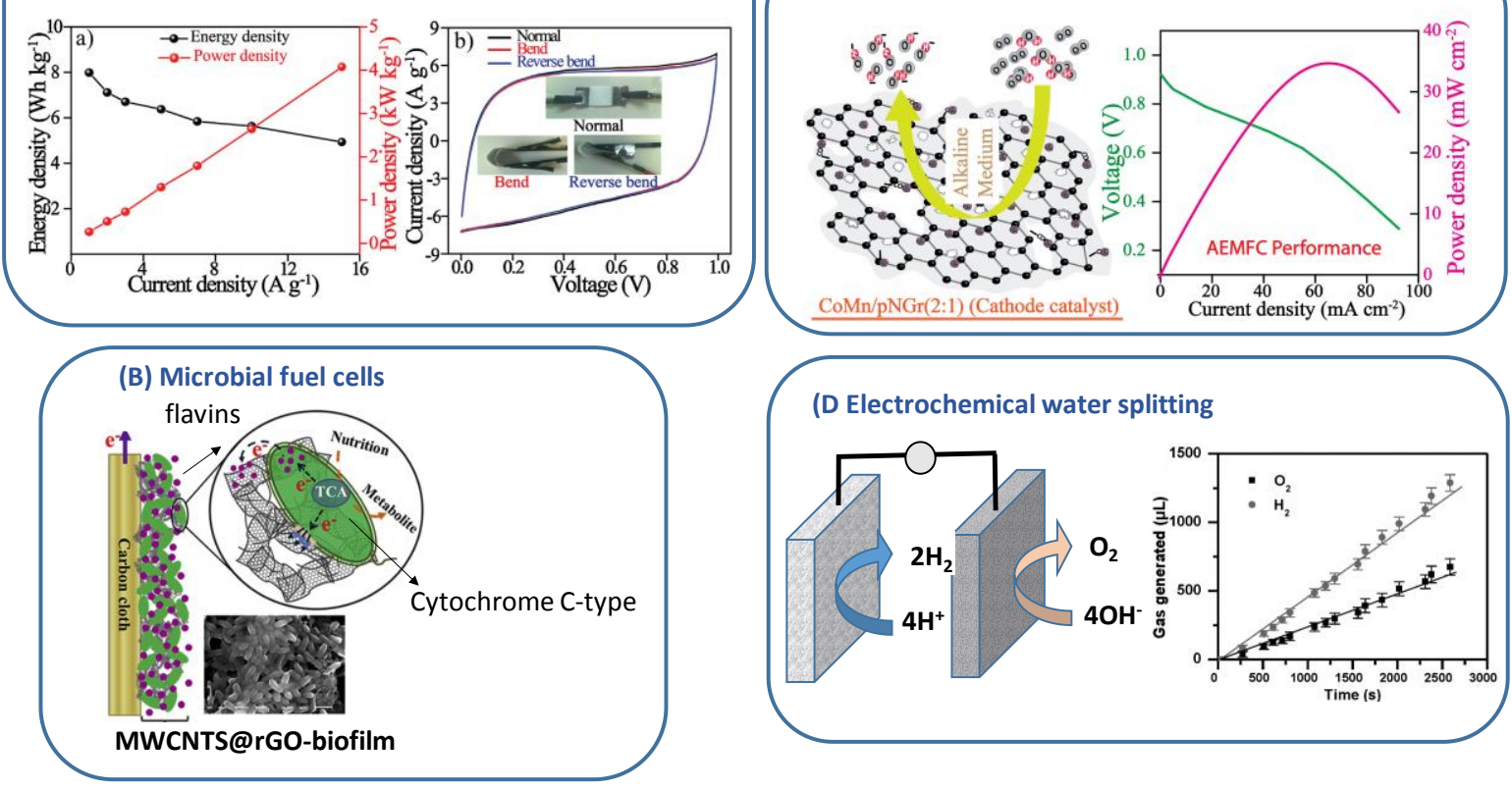

Figure 2: Selected examples for energy and electrocatalytic driven applications: (A) Electrochemical testing of an all solid-state supercapacitor device fabricated with N-doped porous rGO: (a) Plots of the energy density and power density as a function of chargedischarge current density and (b) demonstration of flexibility of the device with different bending states (reprint with permission from Ref.[31]); (B) Mechanism of anodic biofilm on enhanced bioelectrocatalysis; (C) (left) ORR using CoMn/N-doped prGO (2:1) as cathode catalyst, (right) power density of a primary $\mathrm{Zn}$-air battery using this cathode catalyst [27]; (D) (left) Schematic of electrochemical water splitting, (right) $\mathrm{O}_{2}$ and $\mathrm{H}_{2}$ production volume as a function of water splitting time (reprint permission from Ref.[30]).

\section{Sensing and biomedical applications}

The attractive properties of rGO based nanomaterials have paved more recently the way for the fabrication of a wide range of electrochemical based biosensors with improved analytical performance [32-34]. The underlying principle of an electrochemical sensor is to convert a biological binding event into a measurable electrical signal. This approach is represented by electron transfer between the rGO coated interfaces and an electroactive species, which can be either the molecule to be analyzed or a species, whose electrochemical signal correlates with the presence of the target analyte. Aspects governing electron transfer on graphene coated electrodes become of importance to obtain large output signals, allowing to reach low detection limits needed when analyzing clinical samples. Impressive electrocatalytic performance was obtained on multi-layered graphene flakes coated Si wafers in response to biomolecules such as dopamine and ascorbic acid due to the large area of edge planes that are available on such an interface to allow rapid heterogeneous electron transfer [35]. The other advantages of rGO in the electroanalytical context is the high surface area of rGO supporting 
the integration of a high density of analyte specific ligand. Nickel [36] and copper oxide [37] supported on rGO or ammonia-doped porous rGO allowed non-enzymatic glucose sensing due to the electro-catalytic properties of the nanostructures for glucose under alkaline conditions with a $0.25 \mu \mathrm{M}$ detection limit in the case of using $\mathrm{N}$-doped prGO/CuO modified electrodes (Figure 3A) [37]. In a similar manner, non-enzymatic sensing of hydrogen peroxide can be achieved using Pt NPs modified rGO-chitosan-ferrocene carboxylic acid structures,[38] hollow $\mathrm{TiO}_{2}$-rGO microspheres encapsulating hemoglobin,[39] or Au@Prussian blue core-shell structures embedded onto rGO,[40] with detection limits in the nanomolar range.

Real-time quantitative monitoring of biomarkers, a specific class of biological substances whose expression in serum and saliva correlates with a certain illness, has become essential for early detection of the disease, directing personalized treatments and analysis of treatment efficacy. An immunosensing platform for the electrochemical detection of oral cancer, based on anti-IL8/Au NPs-rGO coating, was recently proposed [41]. Porous rGO electrodes modified with anti-gliadin antibodies using 1-pyrenecarboxylic acid as linker molecule to porous reduced graphene oxide ( $\mathrm{prGO}$ ) allowed for sensitive sensing of gliadin in food samples (Figure 3B) [42]. We have also demonstrated that an rGO modified electrode can analyze the level of folic acid protein in human serum with a picomolar detection limit,[43] while molybdenum disulfide-rGO hybrid electrode allowed the direct detection of folic acid in human serum with a limit of detection $10 \mathrm{nM}$ [44]. rGO and/or porous rGO modified electrodes are also highly adapted as general platforms for the efficient on-demand delivery of a variety of drugs using electrochemical triggered approach (Figure 3C), as shown for the controlled delivery of a therapeutic protein such as insulin,[45] an anticancer drug like doxorubicin,[46] ondansetron, an antagonist to prevent nausea and vomiting caused by chemotherapy,[47] as well antibiotics such as ampicillin [47]. Porous rGO (prGO) has, in addition, found its interest for the analysis of protein aggregation in pharmaceutical formulations (Figure 3D) [48]. 
(A) Non-enzymatic glucose sensing on $\mathrm{N}$-doped prGO/CuO

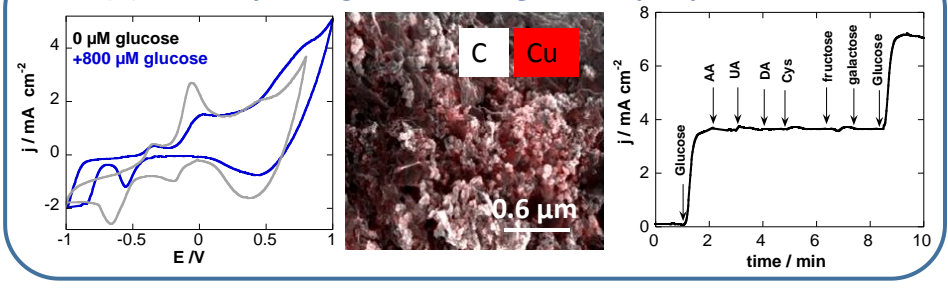

(C) Electrochemical triggered on-demand delivery of therapeutics

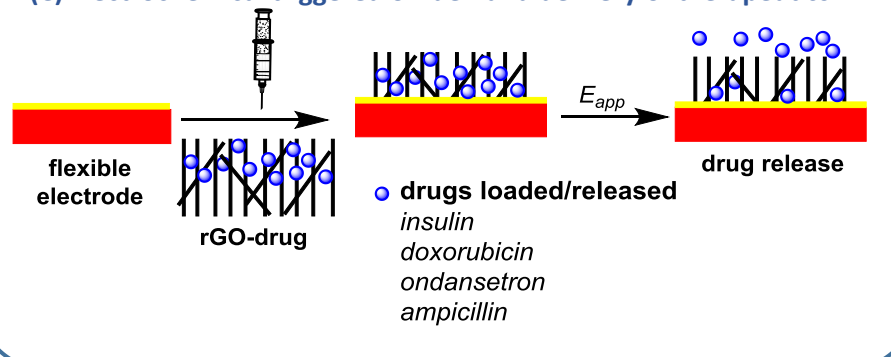

(B) Immunosensor: analysis of gluten in food
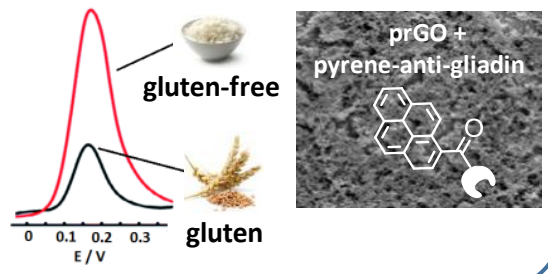

(D) Analysis of protein aggregation

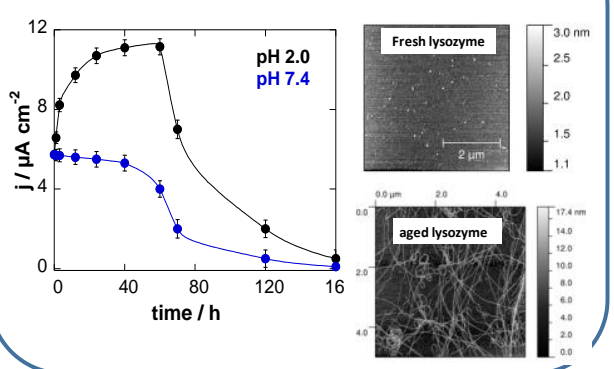

Figure 3: Selected examples of the use of rGO and prGO modified electrodes for biomedical applications: (A) Non-enzymatic glucose sensing: (left) CV of N-doped $\mathrm{prGO} / \mathrm{CuO}$ electrode in the absence and presence of glucose $(800 \mu \mathrm{M})$ in $0.1 \mathrm{M} \mathrm{NaOH}$, (middle) EDX analysis of $\mathrm{N}$-doped prGO/CuO electrodes, (right) Amperometric response to 1 $\mathrm{mM}$ glucose and $10 \mathrm{mM}$ interfering species such as ascorbic acid (AA), uric acid (UA), dopamine (DA), cysteine (Cys), fructose, galactose in $0.1 \mathrm{M} \mathrm{NaOH} \mathrm{[37];} \mathrm{(B)} \mathrm{(left)}$ Differential pulse voltammograms of anti-gliadin modified prGO electrodes in the absence and presence of gliadin using $\mathrm{Fe}(\mathrm{CN})_{6}{ }^{3-}(5 \mathrm{mM}) / \mathrm{PBS}(0.1 \mathrm{M})$ as a redox couple, (right) SEM image of prGO based immunosensor [42]; (C) Schematic illustration of formation of drug loaded graphene based electrodes and electrochemically triggered on demand release; (D) (left) Change in oxidation current density of a lysozyme solution $(700 \mu \mathrm{M})$ submitted to forced degradation at $\mathrm{pH} 2$ and $\mathrm{pH}$ 7.7, (right) AFM image of a fresh lysozyme solution and an aged one [48].

\section{Opinion for potential users of graphene in electrochemical methods}

The rich electrochemistry of graphene is due to its intrinsic favorable properties to molecules of aromatic structure, where $\pi-\pi$ stacking interactions can result in enhanced and better defined electrochemical signals [35], and the ease by which catalytic sites in form of nanoparticles and others can be irreversible anchored onto graphene-based materials. While there has been tremendous progress in the development of graphene based materials, there is still room for further research on the determination of underlying reasons for the activity of graphene, such as the insight which established that ORR catalysis on $\mathrm{N}$-doped graphene stems from the electron-deficient carbon neighboring pyridine nitrogen. In the case of electrochemical sensors, even though a large amount of graphene based sensors are reported in the literature exhibiting good sensing characteristics, the performance in real biological samples, where next to a variety of other proteins high salt concentrations are present, is often 
not considered and information is largely lacking. These are only one of the different challenges to overcome, in order to bring some of the current sensors into real biomedical applications. The realization of graphene-based, next-generation electrochemical guided applications, depends in addition essentially on a reproducible, large-scale production of graphene. The large scale production of monolayer graphene films by of chemical vapor deposition (CVD) in uniform and homogenous manner remains a key challenge. The limited mechanical properties and stability of CVD graphene in solution are one of the most significant obstacles for its use in graphene-based flexible devices. The mass production of high-quality GO and rGO, achieved by chemical oxidation/reduction and exfoliation of lowcost graphite, is on the other hand a promising way to connect to real-world applications and commercialized products. Much effort has thus been more lately devoted into assembling well dispersed multifunctional chemically reduced graphene oxide nanosheetes onto and into ordered macrostructures without loss of their electrochemical properties and keeping mechanical strength and conductivity. Such flexible light-weight and functional materials are of interest for classical energy driven applications (fuel cells, Li-ion batteries, supercapacitors) as well as wearable energy systems and sensors.

\section{CONCLUSION AND OUTLOOK}

The above examples are not an exhaustive list of applications where graphene based materials have resulted in innovative electrochemical applications. It is rather a collection of relevant examples from the literature from different research teams with different perspectives and should serve as triggering further interest in graphene-based electrochemistry. They were chosen as they underline important advancements where graphene was the core of the improvement. It is with no doubt, that this field is currently advancing mainly by developing and finding the miracle material. Basic electrochemical concepts remain mainly untouched, but are essential in understanding mechanistic aspects and potential limitations/advantages of different graphene nanostructures. With the rapid progress that has been made in the last two years on the synthetic aspects of graphene related materials together with advances in in situ spectroscopic methods and powerful theoretical modeling, it is certain that the next five years will be fruitful for advancing graphene-based electrochemical technological inventions. One of the limitations of graphene-based materials remains certainly the variation of the chemical composition and metal contamination, depending on the origin of the graphite precursor and oxidation process conditions. Although for certain applications, this would not affect much their performance, for catalytic and electrocatalytic applications, the nature and concentration 
of metal contaminant can have a huge impact on the performance and reproducibility of the electrode material.

\section{Acknowledgements}

This work has emanated in part from research conducted with the financial support from the Centre National de la Recherche Scientifique (CNRS), the University of Lille, the Hauts-deFrance region, the CPER "Photonics for Society", the Agence Nationale de la Recherche (ANR) through FLAG-ERA JTC 2015-Graphtivity and the EU through the Marie Sklodowska-Curie action (H2020-MSCA-RISE-2015, PANG-690836).

\section{References and recommended reading}

Papers of particular interest, published within the period of review, have been highlighted as:

-Paper of special interest

•Paper of outstanding interest

1.* Chen Y, Yang K, Jiang B, Li J, Zeng M, Lei Fu L: Emerging two-dimensional nanomaterials for electrochemical hydrogen evolution. J. Mater. Chem. A 2017, 5:8187-8208

Important as a recent comprehensive overview on 2D materials for electrocehmical hydrogen evolution.

2. Wang L, Xiong Q, Xiao F, Duan H: 2D nanomaterials based electrochemical biosensors for cancer diagnosis. Biosens. Bioelectron. 2017, 89:136-151.

3. Khan AH, Ghosh S, Pradhan B, Dalui A, Shrestha LK, Acharya S, Ariga K: Twodimensional (2D) nanomaterials towards electrochemical nanoarchitectonics in energy-related applications. Bull. Chem. Soc. Jpn 2017, 90:627.

4. Boukherroub R, Szunerits S: Graphene based biosensors Interface Focus 2017, accepted. add DOI if any

5. Ambrosi A, Chua CK, Bonanni A, Pumera M: Electrochemistry of Graphene and Related Materials. Chem. Rev. 2014, 114:7150-7188.

6. Mao X, Rutledge GC, Hatton TA: Carbon Nanofiber-, Carbon Nanotube- and Graphene-Based Electrochemical Systems for Sensing, Electrocatalysis, and Energy Storage. Nano Today 2014, 9:405-432.

7.* Mao X, Guo F, Yan EH, Rutledge GC, Hatton TA: Remarkably High Heterogeneous Electron Transfer Activity of Carbon-Nanotube-Supported Reduced Graphene Oxide. Chem. Mater. 2016, 28:7422-7432.

Important to show high heterogeneous electron transfer on graphene composites

8.* Ambrosi A, Chua CK, Latiff NM, Loo AH, Wong CHA, Eng AYS, Bonanni A, Pumera M: Graphene and its electrochemistry-an update. Chem. Soc. Rev. 2016, 45:2458. Important as a recent comprehensive overview on 2D materials

9. Velicky M, Brdley DF, Cooper AJ, Hill EW, Kinloch IA, Mishchenko A, Novoselov KS, Patten HV, Toth PS, Valota AT, et al.: Electron transder kinetics on mono and mulitlayer graphene. ACS Nano 2014, 8:10089-10100. 
10. Ritzert NL, Rodriguez-Lopez J, Tan C, Abruna HD: Kinetics of interfacial electron transfer at single-layer graphene electrodes in aqueous and nonaqueous solutions. Langmuir 2013, 29:1683-1694.

11. Valota AT, kinloch IA, Novoselov KS, Casiraghi C, Eckmann A, Hill EW, Dryfe RAW: Electrochemical behavior of monolayer and bilayer graphene. ACS Nano 2011, 5:8809-8815.

12. Li W, Tan C, Lowe MA, Abruna HD, Ralph DC: Elecrochemistry of individual monolayer graphene sheets. ACS Nano 2011, 5:2264_2270.

13. Guell AG, Ebejer N, Snowden ME, MacPherson JV, Unwin PR: Correlations in heterogenopus electron transfer at monolyaer and multilayer graphene. J. Am. Chem. Soc. 2012, 144:7258-7261.

14. Zhou M, Zhai Y, Dong S: Electrochemical Sensing and Biosensing Platform Based on Chemically Reduced Graphene Oxide. Anal. Chem. 2009, 81:5603-5613.

15. Tang L, Wang Y, Li Y, Feng H, Lu J, Li J: Preparation, Structure, and Electrochemical Properties of Reduced Graphene Sheet Films. Adv. Funct. Mater 2009, 19:2782-2789

16. Youn DH, Stauffer SK, Xiao P, Park H, Nam Y, Dolocan A, Henkelman G, Heller A, Buddie Mullins CB: Simple Synthesis of Nanocrystalline Tin Sulfide/N-Doped Reduced Graphene Oxide Composites as Lithium Ion Battery Anodes. ACS Nano 2016, 10:10778-10788.

17.** Lin D, Liu Y, Liang Z, Lee H-W, Sun J, Wang H, Yan K, Xie J, Cui Y: Layered reduced graphene oxide with nanoscale interlayer gaps as a stable host for lithium metal anodes. Nat. Nanotechnol. 2016, 11:626.

This paper is unique in demonstrating a high stable Li metal anode using a layered LirGO composite, important for high enery and high power Li battery systems.

18. Li T, Qin A, Yang L, Chen J, Wang Q, Zhang D, Yang HY: In Situ Grown $\mathbf{F e}_{2} \mathbf{O}_{3}$ Single Crystallites on Reduced Graphene Oxide Nanosheets as High Performance Conversion Anode for Sodium-Ion Batteries. ACS Appl. Mater. Interfaces 2017, 14:19900-19907.

19.** Kim MS, Lim E, Kim S, Jo C, Chun J, Lee J: General Synthesis of N-Doped Macroporous Graphene-Encapsulated Mesoporous Metal Oxides and Their Application as New Anode Materials for Sodium-Ion Hybrid Supercapacitors. $A d v$. Funct. Mater 2017, 27:1603921-1603930.

This paper is unique in demonstrating $\mathrm{Na}^{+}$intercalation/de-intercalation of $\mathrm{WO}_{3-\mathrm{x}} @ \mathrm{~N}$ doped macroporous graphene.

20. Mo R, Rooney D, Sun K, Yang HY: 3D nitrogen-doped graphene foam with encapsulated germanium/nitrogen-doped graphene yolk-shell nanoarchitecture for high-performance flexible Li-ion battery. Nat. Commun. 2016, 8:13949.

21. Xu J, Chen J, Zhang M, Hong J-D, Shi G: Highly Conductive Stretchable Electrodes Prepared by In Situ Reduction of Wavy Graphene Oxide Films Coated on Elastic Tapes. Adv. Electron. Mater. 2016, 2:1600022-1600030.

22. Simon P, Gogotsi Y: Materials for Electrochemical Capacitors. Nat. Mater. 2008, 7:845-854.

23. Chee WK, Lim HN, Zainal Z, Huang NM, Harrison I, Andou Y: Flexible GrapheneBased Supercapacitors: A Review. J. Phys. Chem. C 2016, 120:4153-4172.

24. Pettong T, Iamprasertkun P, Krittayavathananon A, Sukha A, S P, Seubsai A, Chareonpanich M, Kongkachuichay P, Limtrakul J, Sawangphruk M: HighPerformance Asymmetric Supercapacitors of $\mathrm{MnCo}_{2} \mathrm{O}_{4}$ Nanofibers and N-Doped Reduced Graphene Oxide Aerogel. ACS Appl. Mater. Interfaces 2016, 8:3404534053. 
25. Zou L, Qiao Y, Wu X-S, Li CM: Tailoring hierarchically porous graphene architecture by carbon nanotube to accelerate extracellular electron transfer of anodic biofilm in microbial fuel cells. J. Power Sources 2016, 328:143-150.

26. Nie Y, Li L, Wei Z: Recent advancements in Pt and Pt-free catalysts for oxygen reduction reaction Chem. Soc. Rev. 2015, 44:2168-2201.

27.* Sing SS, Kashyap V, Manna N, Bhange SN, Soni R, Boukherroub R, Szunerits S, Kurungot S: Efficient and Durable Oxygen Reduction Electrocatalyst Based on CoMn Alloy Oxide Nanoparticles Supported Over N-Doped Porous Graphene. ACS Catal. 2017, 7:6700-6710.

Important as it shows the interest of a oxygen reduction catalyst such as CoMn-porous nitrogen-doped $\mathrm{rGO}$ in a primary Zn-air battery.

28. Song F-Z, Zhu Q-L, Yang X, Zhan W-W, Pachfule P, Tsumori N, and Qiang Xu Q: Metal-Organic Framework Templated Porous Carbon-Metal Oxide/Reduced Graphene Oxide as Superior Support of Bimetallic Nanoparticles for Efficient Hydrogen Generation from Formic Acid. Adv. Energy Mater. 2017:17014161701421.

29. Zheng Y, Jiao Y, Zhu Y, Li LH, Han Y, Chen Y, Du A, Jaroniec M, Qiao SZ: Hydrogen evolution by a metal-free electrocatalyst. Nat. Commun. 2014, 5:3738.

30.** Zhang J, Dai L: Nitrogen, Phosphorus, and Fluorine Tri-doped Graphene as a Multifunctional Catalyst for Self-Powered Electrochemical Water Splitting. Angew. Chem. Int. Ed. 2016, 55:13296-13300.

The paper is unique as it shows self-powered electrocehmical water splitting on a tridoped graphene matrixe.

31. Sing SS, Dhavale V, Boukherroub R, Kurungot S, Szunerits S: N-doped porous reduced graphene oxide as an efficient electrode material forhigh performance flexible solid-state supercapacitor. Appl. Mater. Today 2017, 8:141-149.

32. Bunyakul N, Baeumner AJ: Combining Electrochemical Sensors with Miniaturized Sample Preparation for Rapid Detection in Clinical Samples. Sensors 2015, 15:547564.

33. Ibau C, Arhsad MK, Gopinath SCB: Current advances and future visions on bioelectronic immunosensing for prostate-specific antigen. Biosens. Bioelectron. 2017, 98:267-284.

34. Turcheniuk K, Boukherroub R, Szunerits S: Gold-graphene nanocomposites for sensing and biomedical applications. J. Mater. Chem. B 2015, 3:4301-4324

35. Shang NG, Papakonstantiou P, McMullan M, Chu M, Stamnoulis A, Potenza A, Dhesi SS, Marchetto H: Catalyst-Free Efficient Growth, Orientation and Biosensing Properties of Multilayer Graphene Nanoflake Films with Sharp Edge Planes. $A d v$. Func. Mater. 2008, 18:3506-3514.

36. Subramanian P, Niedziolka-Jonsson J, Lesniewski A, Wang Q, Li M, Boukherroub R, Szunerits $\mathrm{S}$ : Preparation of reduced graphene oxide- $\mathrm{Ni}(\mathrm{OH})_{2}$ composites by electrophoretic deposition: application for non-enzymatic glucose sensing. J. Mater. Chem. A 2014, 2:5525-5533.

37. Maaoui H, Singh SK, Teodorescu F, Coffinier Y, Barras A, Chtourou R, Kurungot S, Szunerits S, Boukherroub R: Copper oxide supported on three-dimensional ammonia-doped porous reduced graphene oxide prepared through electrophoretic deposition for non-enzymatic glucose sensing. Electrochim. Acta 2017, 224:346-354.

38. Bai Z, Li G, Liang J, Su J, Zhang Y, Chen H, Huang Y, Sui W, Zhao Y: Nonenzymatic electrochemical biosensor based on Pt NPs/RGO-CS-Fc nano-hybrids for the detection of hydrogen peroxide in living cells. Biosens. Bioelectron. 2016, 82:185-194. 
39. Liu H, Guo K, Duan C, Dong X, Gao J: Hollow TiO 2 modified reduced graphene oxide microspheres encapsulating hemoglobin for a mediator-free biosensor. Biosens. Bioelectron. 2017, 87:473-479.

40. Zhang M, Halder A, Hou C, Ulstrup J, Chi Q: Free-standing and flexible graphene papers as disposable non-enzymatic electrochemical sensors. Bioelectrochemistry. 2016, 109:87-94.

41. Verma S, Singh A, Shukla A, Kaswan J, Arora K, Ramirez-Vick J, Singh P, Singh SP: Anti-IL8/AuNPs-rGO/ITO as an Immunosensing Platform for Noninvasive Electrochemical Detection of Oral Cancer. ACS Appl. Mater. Interfaces 2017, 9:27462.

42. Chekin F, Sing SS, Vasilescu A, Dhavale V, Kurungot S, Boukherroub R, Szunerits S: Reduced Graphene Oxide Modified Electrodes for Sensitive Sensing of Gliadin in Food Samples. ACS Sens. 2016, 1:1462-1470.

43. He L, Wang Q, Mandler D, Li M, Boukherroub R, Szunerits S: Detection of folic acid protein in human serum using reduced graphene oxide electrodes modified by folic-acid. Biosens. Bioelectron. 2016, 75:389-395.

44. Chekin F, Teodorescu F, Coffinier Y, Pan G-H, Barras A, Boukherroub R, Szunerits S: $\mathrm{MoS}_{2} /$ reduced graphene oxide as active hybrid material for the electrochemical detection of folic acid in human serum. Biosens. Bioelectron. 2016, 85:807-813.

45.** Teodorescu F, Rolland L, Ramarao V, Abderrahmani A, Mandler D, Boukherroub R, Szunerits $S$ : Electrochemically triggered release of human insulin from an insulinimpregnated reduced graphene oxide modified electrode. Chem. Commun. 2015, 51:14167-14170

Unique as it shows that electrochemical triggered insulin release from rGO electrodes results in the release of therapeutic amounts without affecting the biological activity of insulin

46. He L, Sarkar S, Barras A, Boukherroub R, Szunerits S, Mandler D: Electrochemically stimulated drug release from flexible electrodes coated electrophoretically with doxorubicin loaded reduced graphene oxide. Chem. Commun. 2017, 53:4022-4025

47. Boulahneche S, Jijie R, Barras A, Chein F, Sing SS, Bouckaert J, Medjram MS, Kurungot S, Boukherroub R, Szunerits S: On demand electrochemical release of drugs from porous reduced graphene oxide modified flexible electrodes. J. Mater. Chem. B 2017, 5: 6557-6565.

48. Vasilescu A, Boulahneche S, Chekin F, Gáspár S, Medjram MS, Diagne AA, Singh SK, Kurungot S, Boukherroub R, Szunerits S: Porous reduced graphene oxide modified electrodes for the analysis of protein aggregation. Part 1: Lysozyme aggregation at pH 2 and 7.4. Electrochim. Acta 2017, 254:375-383. 